\title{
Influence of Ag on the Chemical and Thermal Compatibility of LSCF- SDCC for LT-SOFC
}

\author{
Linda Agun ${ }^{1, a}$, Muhammad Subri Abu Bakar ${ }^{1, b}$, Sufizar Ahmad ${ }^{1, c}$, \\ Andanastuti Muchtar ${ }^{2, \mathrm{~d}}$, and Hamimah Abd.Rahman ${ }^{1, \mathrm{e}}$ \\ ${ }^{1}$ Faculty of Mechanical and Manufacturing Engineering, Universiti Tun Hussein Onn Malaysia, \\ 86400 Parit Raja, Batu Pahat, Johor, Malaysia \\ ${ }^{2}$ Faculty of Engineering and Built Environment, Universiti Kebangsaan Malaysia, 43600 Bangi, \\ Selangor, Malaysia \\ agd130011@siswa.uthm.edu.my, bmsubri21812@gmail.com, 'sufizar@uthm.edu.my, \\ dmuchtar@eng.ukm.my, ${ }^{*}$ hamimah@uthm.edu.my
}

\section{Keywords: LSCF, Silver, Thermal expansion, LT-SOFC}

\begin{abstract}
In addition to the good electrochemical performance criteria in solid oxide fuel cell (SOFC) applications, cathode material must match thermal expansion with other SOFC components. Thus, effects of Ag on thermal mismatch, chemical reactions, and microstructure are investigated. $\mathrm{Ag}\left(1 \mathrm{wt} \%\right.$ to $5 \mathrm{wt} \%$ ) was mixed with $\mathrm{La}_{0.6} \mathrm{Sr}_{0 \cdot 4} \mathrm{Co}_{0 \cdot 2} \mathrm{Fe}_{0 \cdot 8} \mathrm{O}_{3-\delta}(\mathrm{LSCF} 6428)$ and Smdoped ceria carbonate (SDCC) composite cathode powder. LSCF6428-SDCC-Ag samples were sintered at $600{ }^{\circ} \mathrm{C}$ for $2 \mathrm{~h}$. The thermal expansion coefficients (TECs), which were determined using a dilatometer, indicated relatively less TEC mismatch between LSCF-SDCC-Ag cathodes composite and SDCC electrolyte. The average TEC value obtained from $20^{\circ} \mathrm{C}$ to $600{ }^{\circ} \mathrm{C}$ implied that LSCF-SDCC-A5 (5 wt. \% Ag) showed better thermal matching $\left(13.18 \times 10^{-6} \mathrm{~K}^{-1}\right)$ with SDCC electrolyte $\left(12.84 \times 10^{-6} \mathrm{~K}^{-1}\right)$ and achieved better compatibility. The X-ray diffraction patterns indicated that the LSCF6428-SDCC-Ag peak increased with the increase in the amount of Ag. Scanning electron microscopy analysis showed that Ag was capable of maintaining the porosity that is required for cathodes $(20 \%-40 \%)$. Results showed that $\mathrm{Ag}$ exhibited desirable thermal and chemical compatibility with LSCF-SDCC. Thus, LSCF6428-SDCC-Ag can be used as a composite cathode for low-temperature SOFCs.
\end{abstract}

\section{Introduction}

Fuel cells allow the direct conversion of chemically stored energy into electrical energy by means of electrochemical oxidation of various fuels. Solid oxide fuel cells (SOFCs) are considered to be among the most promising fuel cells and have been investigated in energy conversion devices with high efficiency, low pollution emission, and extensive fuel flexibility. In SOFCs, an oxygen reduction reaction occurs at the cathode to produce oxygen anions, which then move through a dense oxygen ion-conducting electrolyte to the anode [1]. The cathodes for low-temperature (LT)SOFCs should possess high electrical and ionic conductivities, enhanced electrode reaction activity, long-term stability, and adequate porosity for gas transport [2]. In SOFC applications, a satisfactory cathode material must meet other requirements such as a thermal expansion match with other components [3]. Thermal expansion coefficient (TEC) is one of the most important factors that ensure reliability of a SOFC system [4].

All of the SOFC components are solid and thus, mismatches in TECs between materials can become a serious problem during fabrication or at thermal cycles during operation. A difference in TEC between a cathode and an electrolyte at $7 \times 10^{-6} \mathrm{~K}^{-1}$ can result in a $10 \%$ chance of delamination occurring at the first $500 \mathrm{~h}$ of operational [4]. Therefore, the TEC of perovskite has to be considered and should be matched with the electrolyte to avoid a high mismatch with the electrolyte. An excessively high stress can lead to possible delamination at the interface [5]. The trend of TEC value demonstrates that increased electrolyte amounts in the composite cathode bring the TEC of 
the cathode closer to that of the electrolyte [6]. A TEC difference of less than $10 \%$ [6] between the cathode and the electrolyte is suitable for mechanical compatibility to prevent delamination during processing or applications at elevated temperatures. Thus, developing cathode materials with high electrocatalytic activity is necessary to ensure oxygen reduction reaction and high oxygen ion conductivity for oxygen transport through the composite cathode at LTs; such cathode materials should also exhibit less thermal compatibility mismatch. Ag, which has excellent catalytic activity for oxygen reduction, is applied in LSCF6428-SDC with $14.4 \times 10^{-6} \mathrm{~K}^{-1}$ TEC value [7] to develop an operable LT-SOFC [8]. The use of Ag in composite cathode has been reported by various researchers [8-10]. Ag is also a potential candidate because of its relatively low cost, high electrical conductivity, capability of reducing surface resistance and improving the efficiency of current collection from the cathode, and its ability to realize the LT sintering process [8]. The melting point of $\mathrm{Ag}$ is $961.78^{\circ} \mathrm{C}$ [2], which limits the operating temperature of SOFCs. However, $\mathrm{Ag}$ operates at LT and is widely used as electrodes for various electrochemical devices; Ag has been used in a SOFC [2]. In the present study, the TEC match and chemical reaction characteristics of the composite cathode LSCF6428-SDCC-Ag are studied with varied amounts of Ag.

Experimental Procedure. First, 1, 3, and 5 wt.\% Ag (Sigma-Aldrich, Malaysia) was mixed with composite LSCF-SDCC cathode powders. A mixture of $80 \mathrm{wt} \%$ SDC nanopowder (Sigma-Aldrich, Malaysia) with 20 wt.\% carbonates $\left(67\right.$ mol. $\% \mathrm{Li}_{2} \mathrm{CO}_{3}: 33$ mol.\% $\left.\mathrm{Na}_{2} \mathrm{CO}_{3}\right)$ was prepared through conventional solid-state reaction. Subsequently, $50 \mathrm{wt} \%$ SDCC electrolyte powder was mixed with 50 wt.\% perovskites LSCF6428 (Kceracell, Taiwan) powder. Using low energy milling speed, the Ag was dry milled together with LSCF-SDCC using a milling machine (Fritsch Pulverisette 6, Germany). The LSCF-SDCC-Ag composite powders were then ground in an agate mortar and calcined at $750{ }^{\circ} \mathrm{C}$ for $2 \mathrm{~h}$ with a heating rate of $5{ }^{\circ} \mathrm{C} \min ^{-1}$ to obtain the desired composite cathode powder. The composition based on Ag amount is shown in Table 1. Uniaxial press method was used to prepare cylindrical samples $(20 \mathrm{~mm}$ long and $6 \mathrm{~mm}$ in diameter) of LSCF-SDCC-Ag composite cathode for TEC analysis. The samples were then sintered at $600{ }^{\circ} \mathrm{C}$ for $2 \mathrm{~h}$.

Table 1. Composition of composite cathode with varied amounts of Ag

\begin{tabular}{cc}
\hline Samples & Ag [wt.\%] \\
\hline LSCF-SDCC & - \\
LSCF-SDCC-A1 & 1 \\
LSCF-SDCC-A3 & 3 \\
LSCF-SDCC-A5 & 5 \\
\hline
\end{tabular}

Characterization Method. X-ray diffraction (XRD, Bruker D8 Advance) was used to identify the chemical compatibility of LSCF6428-SDCC-Ag cell using $\mathrm{Cu}$ Ka radiation $(\lambda=0.15406 \mathrm{~nm})$ at room temperature. The diffraction patterns were collected by step scanning at $0.02^{\circ}$ in the $2 \theta$ range of $20^{\circ}$ to $80^{\circ}$. The relative TEC was measured in air from room temperature to $600{ }^{\circ} \mathrm{C}$ at $5{ }^{\circ} \mathrm{C}$ $\mathrm{min}^{-1}$. The TECs of the samples were measured using a horizontal push rod dilatometer (Netzsch DIL 402C) with an $\mathrm{Al}_{2} \mathrm{O}_{3}$ reference. The surface morphology and homogeneity of the cathode composite were observed via scanning electron microscopy (SEM, Zeiss Evo MA, UK). Porosity and density were evaluated using the Archimedes principle.

Results and Discussion. Chemical compatibility for various concentrations of $\mathrm{Ag}$ on sintered LSCF-SDCC-Ag samples was examined via XRD test with 03-065-2871 as reference pattern (Fig. 1). The XRD patterns illustrate that the increase in peak intensities was due to the increase in Ag concentration. The XRD results showed that Ag formed a cubic structure. The introduction of Ag into the composite LSCF6428-SDCC cathode did not affect its composite cathode structure because no secondary peaks appeared after the powder preparation process [9]. The absence of secondary 
peaks means that the components in the composite cathode yielded better results with their own function and advantages.

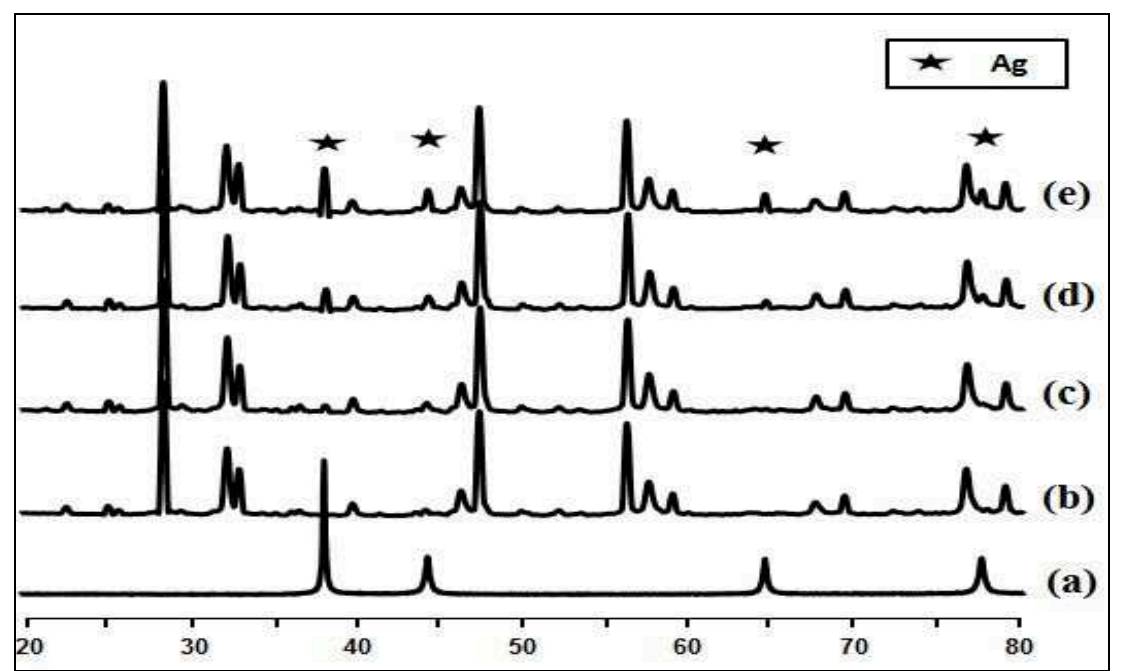

Fig. 1. XRD patterns of purity composite cathode: (a) Ag; (b) LSCF-SDCC; (c) LSCF-SDCC-A1;

(d) LSCF-SDCC-A3; and (e) LSCF-SDCC-A5.

The porosity and density results indicate that the addition of $\mathrm{Ag}$ increased the bulk density and decreased the porosity of LSCF-SDCC-Ag composite cathode. The porosity of the composite cathode without $\mathrm{Ag}$ was 32.80\%; however, the addition of 5 wt.\% Ag reduced the porosity to 27.95\%. The density of the cathode was $3.79 \mathrm{~g} \mathrm{~cm}^{-3}$ without $\mathrm{Ag}$ and $4.08 \mathrm{~g} \mathrm{~cm}^{-3}$ with $5 \mathrm{wt} \% \mathrm{Ag}$ (Fig. 2). Incorporating Ag in the ceramic phase can prevent Ag from sintering, thereby retaining the porosity that is required for a cathode electrode [10]. Retaining the required porosity means that sufficient pores $(20 \%-40 \%)$ are available for transporting oxidants to the electrochemical reaction sites in the cathode [11]. Su et al. [12] demonstrated that incorporating $\mathrm{Ag}$ into the $\mathrm{Ba}_{0.5} \mathrm{Sr}_{0.5} \mathrm{Co}_{0.6} \mathrm{Fe}_{0.4} \mathrm{O}_{3-\delta}$ significantly improves electrocatalytic oxygen reduction performance, enhances current collecting ability, and reduces the electrode ohmic resistance of the cathode.

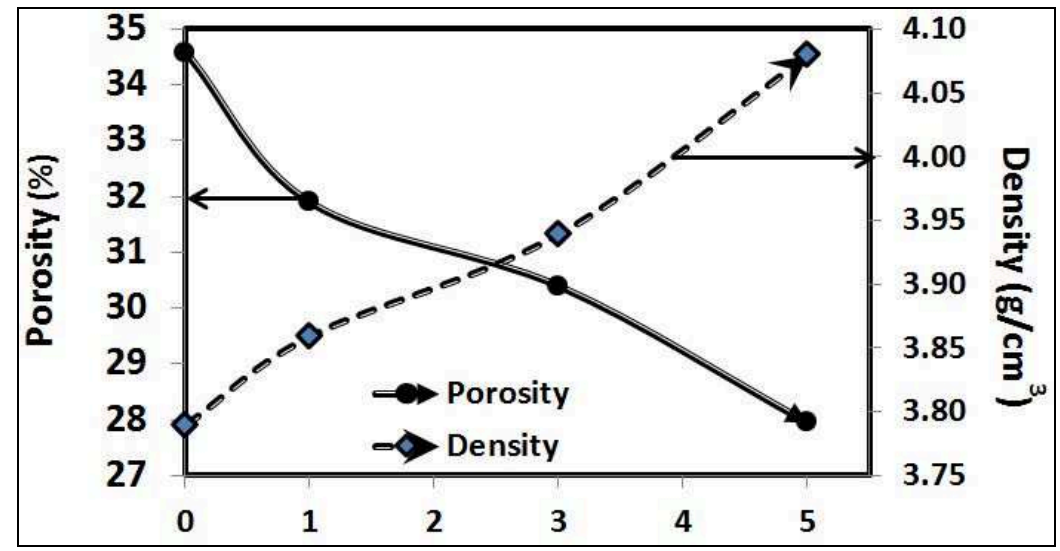

Fig. 2. Porosity and density results for composite cathodes with different Ag concentrations.

Figure 3 shows the SEM micrographs of the composite LSCF-SDCC cathodes (sintered at 600 ${ }^{\circ} \mathrm{C}$ for $2 \mathrm{~h}$ ) with $1 \mathrm{wt} . \%$ to $5 \mathrm{wt} . \% \mathrm{Ag}$. A back-scattered electron detector was used to obtain the SEM images of the composite LSCF6428-SDCC-Ag cathode. Black spots represent pores on the composite LSCF-SDCC-Ag cathode. The observed surface morphology indicated that the addition of $\mathrm{Ag}$ decreased the porosity from $31.90 \%$ to $27.95 \%$ for the cathodes with $1 \mathrm{wt} . \%$ to $5 \mathrm{wt}$. $\% \mathrm{Ag}$, respectively. The observed internal morphology indicated that the composite cathode became dense after the addition of Ag. These results are consistent with porosity and density results. 


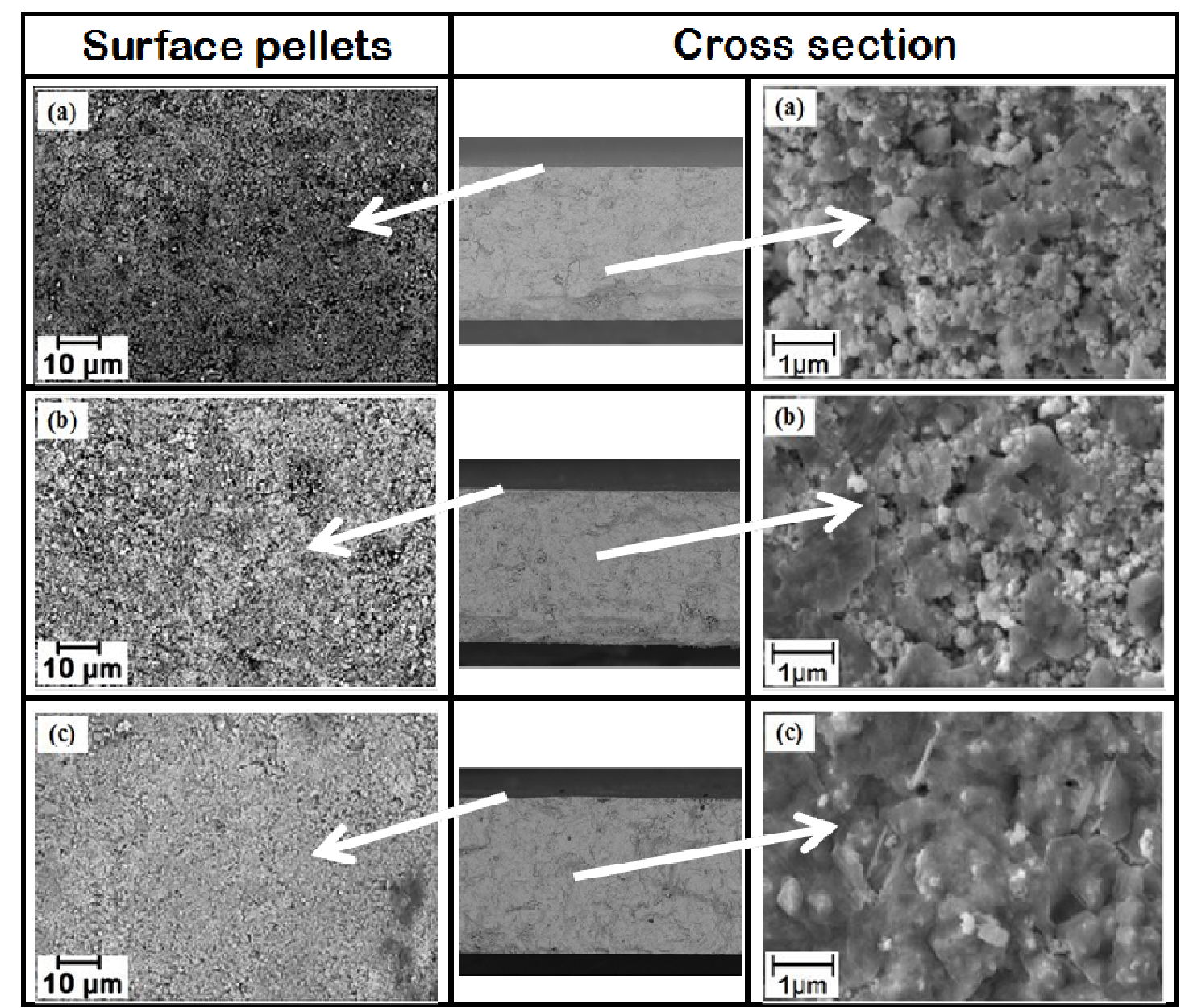

Fig. 3. Morphology of the composite LSCF-SDCC-Ag cathodes (sintered at $600{ }^{\circ} \mathrm{C}$ for $2 \mathrm{~h}$ ) with (a) 1 wt $\%$ $\mathrm{Ag}$, (b) 3 wt. $\% \mathrm{Ag}$, and (c) 5 wt.\% Ag.

The TEC of composite LSCF-SDCC-Ag cathode in the temperature range of $20{ }^{\circ} \mathrm{C}$ to $600{ }^{\circ} \mathrm{C}$ is shown at Table 2, with a composite electrolyte SDCC as a reference. Tietz [5] found that large differences in TEC may induce large internal stress during the actual application, thereby affecting the operational stability of SOFCs. Therefore, preparing a composite cathode with below $7 \times 10^{-6}$ $\mathrm{K}^{-1}$ [4] and $10 \%$ different [6] to avoid delamination [4]. In the present study, the TEC values decreased with the increase in Ag concentration. The addition of 5 wt.\% Ag in LSCF-SDCC gives the lowest TEC mismatch with the SDCC electrolyte at the percentage difference of $2.65 \%$ $\left(0.34 \times 10^{-6} \mathrm{~K}^{-1}\right)$ compared to the LSCF-SDCC with $3 \mathrm{wt} . \% \mathrm{Ag}, 1 \mathrm{wt} . \% \mathrm{Ag}$ and without Ag which yielded a mismatch of $4.36 \%, 5.14 \%$, and $4.21 \%$ respectively. Therefore, in this temperature range and based on this criterion, the LSCF-SDCC-A5 shows the most appropriate matches and potential to improve the performance of LT-SOFC [4].

Table 2. TECs of SDCC electrolyte with LSCF-SDCC-Ag cathode.

\begin{tabular}{|c|c|}
\hline Sample & $\begin{array}{c}\text { Average TEC }\left({ }^{-6} / \mathrm{K}\right) \\
\left(20-600{ }^{\circ} \mathrm{C}\right)\end{array}$ \\
\hline SDCC & 12.84 \\
\hline LSCF-SDCC & 13.38 \\
\hline LSCF-SDCC-A1 & 13.50 \\
\hline LSCF-SDCC-A3 & 13.40 \\
\hline LSCF-SDCC-A5 & 13.18 \\
\hline
\end{tabular}




\section{Conclusions}

Ag exhibited good thermal compatibility with the composite LSCF-SDCC cathode after sintering at $600{ }^{\circ} \mathrm{C}$ for $2 \mathrm{~h}$. Thus, $1 \mathrm{wt} . \%$ to $5 \mathrm{wt} . \%$ of $\mathrm{Ag}$ was appropriate for incorporation with LSCF-SDC composite cathode. Ag plays an important role in improving chemical reactions when the cathodes are used as fine conductors, as well as in decreasing TEC mismatch. The results of this study show that Ag can be used as a metallic catalyst in LSCF-SDCC cathodes for LT-SOFCs.

\section{Acknowledgements}

The authors acknowledge the Malaysian Government for their sponsorship under the grant scheme FRGS-Vot 1220 for the project.

\section{References}

[1] S. Choi, J. Shin, \& G. Kim, The Electrochemical and Thermodynamic Characterization of $\mathrm{PrBaCo}_{2}-\mathrm{x} \mathrm{Fe}_{\mathrm{x}} \mathrm{O}_{5}+\delta(\mathrm{x}=0,0.5,1)$ Infiltrated into Yttria-Stabilized Zirconia Scaffold as Cathodes for Solid Oxide Fuel Cells, J. Power Sources. 201 (2012) 10-17.

[2] S. Huang, G. Zhou, \& Y. Xie, Electrochemical Performances of Ag- $\left(\mathrm{Bi}_{2} \mathrm{O}_{3}\right)_{0.75}\left(\mathrm{Y}_{2} \mathrm{O}_{3}\right)_{0.25}$ Composite Cathodes, J. Alloys and Compd. 464 (2008) 322-326.

[3] J. Raharjo, Performa Elektrokimia Komposit Katoda Berbasis $\mathrm{La}_{0,6} \mathrm{Sr}_{0,4} \mathrm{Co}_{0,2} \mathrm{Fe}_{0,8} \mathrm{O}_{3-\delta}$ Untuk Solid Oxide Fuel Cell Bersuhu Rendah, Indonesian J. Mater. Sci. 13 (2012) 198-203.

[4] Park, K., Yu, S., Bae, J., Kim, H., \& Ko, Y. Fast Performance Degradation of SOFC caused by Cathode Delamination in Long-Term Testing, Int. J. Hydrogen Energy. 35 (2010) 8670-8677.

[5] Tietz, F., Mai, A., \& Stöver, D. From Powder Properties to Fuel Cell Performance - A Holistic Approach for SOFC Cathode Development, Solid State Ionics. 179 (2008) 1509-1515.

[6] Rahman, H. A., Muchtar, A., Muhamad, N., \& Abdullah, HStructure and Thermal Properties of $\mathrm{La}_{0.6} \mathrm{Sr}_{0.4} \mathrm{Co}_{0.2} \mathrm{Fe}_{0.8} \mathrm{O}_{3-\delta}-\mathrm{SDC}$ Carbonate Composite Cathodes for Intermediate-to LowTemperature Solid Oxide Fuel Cells, Ceram. Int. 38 (2012) 1571-1576.

[7] Xu, Q., Huang, D., Zhang, F., Chen, W., Chen, M., \& Liu, H. Structure, Electrical Conducting and Thermal Expansion Properties of $\mathrm{La}_{0.6} \mathrm{Sr}_{0.4} \mathrm{Co}_{0.2} \mathrm{Fe}_{0.8} \mathrm{O}_{3-\delta}-\mathrm{Ce}_{0.8} \mathrm{Sm}_{0.2} \mathrm{O}_{2-\delta}$ Composite Cathodes, J. Alloys and Compd. 454 (2008) 460-465.

[8] T. Suzuki, Y. Takajashi, K. Hamamoto, T, Yamaguchi, Y. Fujishiro, Low Temperature Processed Composite Cathodes for Solid-oxide fuel Cells, Int. J. Hydrogen Energy. 36 (2011) 10998-11003.

[9] Z. Wang, L. Xin, X. Zhao, Y. Qiu, Z. Zhang, O. A. Baturina \& W. Li, Carbon supported Ag Nanoparticles with Different Particle Size as Cathode Catalysts for Anion Exchange Membrane Direct Glycerol Fuel Cells, Renewable Energy. 62 (2014) 556-562.

[10] L. Zhang, L. Li, F. Zhao, F. Chen, C. Xia, $\mathrm{Sm}_{0.2} \mathrm{Ce}_{0.8} \mathrm{O}_{1.9} / \mathrm{Y}_{0.25} \mathrm{Bi}_{0.75} \mathrm{O}_{1.5}$ Bilayered Electrolytes for Low-Temperature SOFCs with $\mathrm{Ag}-\mathrm{Y}_{0.25} \mathrm{Bi}_{0} .75 \mathrm{O}_{1.5}$ Composite Cathodes, Solid State Ionics. 192 (2011) 557-560.

[11] Da Conceição, L., Silva, A. M., Ribeiro, N. F. P., \& Souza, M. M. V. M. Combustion Synthesis of $\mathrm{La}_{0.7} \mathrm{Sr}_{0.3} \mathrm{Co}_{0.5} \mathrm{Fe}_{0.5} \mathrm{O}_{3}$ (LSCF) Porous Materials for Application as Cathode in ITSOFC, Mater. Res. Bulletin. 46 (2011) 308-314.

[12] R. Su, Z. Lü, S.P. Jiang, Y. Shen, W. Su, \& K. Chen, Ag Decorated (Ba,Sr $)(\mathrm{Co}, \mathrm{Fe}) \mathrm{O}_{3}$ Cathodes for Solid Oxide Fuel Cells Prepared by Electroless Silver Deposition, Int. J. Hydrogen Energy. 38 (2013) 2413-2420. 